\title{
Treating organic abulia with bromocriptine and lisuride: four case studies
}

\author{
K Barrett
}

\begin{abstract}
Abulia refers to an impairment of will, or the inability to initiate behaviour and action. There are reports of successful treatment of akinetic mutism, the most severe form of abulia, with bromocriptine. Four case studies are presented describing the successful treatment of abulia at a lesser severity than akinetic mutism with bromocriptine. Abulia was caused by brain damage due to alcohol in two cases, Wilson's disease and basal ganglia infarct in one each. Maximum bromocriptine dose varied from 25$70 \mathrm{mg}$. All improved considerably. Withdrawal or reduction of medication in three produced deterioration. The prescription of a neuroleptic drug had a similar effect in the fourth. One patient with a previous history developed a depressive relapse and so the drug was withdrawn and lisuride introduced. This produced a similar improvement. These cases highlight the value of identifying the syndrome of organic abulia and suggest that dopamine agonists may have a place in its treatment, though controlled studies are needed.
\end{abstract}

Dorlands Medical Dictionary defines abulia as an "inability to perform acts voluntarily or to make decisions." The term derives from the Greek and literally means absence of will. Although widely used in late nineteenth century psychiatry the term fell out of use thereafter, but has been revived in the past decade to describe problems of drive and volition arising as a result of brain damage. Fisher ${ }^{1}$ recommended the use of the term to describe "a specific neurological syndrome comprising slowness, decreased responsiveness, apathy ... Akinetic mutism is its extreme form." Fisher ${ }^{1}$ reviewed the literature on organic abulia/akinetic mutism and described 37 cases from his own clinical experience. The state arose from bilateral cingulate lesions in 11 cases, midbrain/medial diencephalic lesions in 18, hydrocephalus in nine, third ventricle cysts in three. Craniopharyngioma, encephalitis lethargica and trauma accounted for one each. Ross and Stewart ${ }^{2}$ described a patient who became akinetic and mute following the removal of a tumour of the anterior hypothalamus. The state responded to bromocriptine, a dopamine agonist with predominantly post-synaptic action, but not to levodopa or methylphenindate. Improvement, rated using the Karnofsky scale, ${ }^{3}$ occurred only at high doses (90-120 mg/day). Fisher, and Ross and Stewart suggest that the state may arise from loss of dopaminergic input to the anterior cingulate cortex and cite evidence from studies in rat brain of dopaminergic pathways extending from the midbrain through the medial forebrain bundle to the anterior cingulum and basal forebrain. ${ }^{3}$ Eschiveri et $a l^{4}$ subsequently reported four akinetic and mute patients successfully treated with bromocriptine. Crismon et $a l^{5}$ reported specific improvement in intelligibility, spontaneity and articulation of speech in three patients following bromocriptine. The drug was prescribed in an attempt to improve communication skills but it is clear from the reports that the patients were in some degree abulic and that the state improved on doses between 20 and $45 \mathrm{mg} /$ day. Albert et $a l^{6}$ similarly reported improvement in confrontation naming, reduction in response latency and improvement in speech fluency following treatment with bromocriptine $30 \mathrm{mg} /$ day in a patient with left hemisphere damage following cerebral haemorrhage. Deterioration occurred on stopping the drug. Fleet $e a^{7}{ }^{7}$ carried out a one month trial of bromocriptine at a dose of $15 \mathrm{mg} /$ day in an attempt to improve a syndrome of unilateral neglect following right frontal and parietal infarction. Improvement in measures of neglect occurred during the treatment period, but a number of other improvements were also noted including speed of bilateral arm raising, reduction of motor impersistence, orientation to external stimuli and libido. None of these reports noted significant adverse effects from treatment.

The studies cited suggest that not only akinetic mutism but also abulia of lesser severity may respond to bromocriptine. The present paper describes the treatment of four patients with abulia of varying severity arising as a result of brain damage. The figure summarises the cases by rating the change using the Karnofsky scale, ${ }^{3}$ the simple measure of disability used by Ross and Stewart in the paper cited above. ${ }^{2}$

\section{Case 1}

A 28 year old male former university student developed a major depressive disorder at the age of 20 which proved refractory to physical 


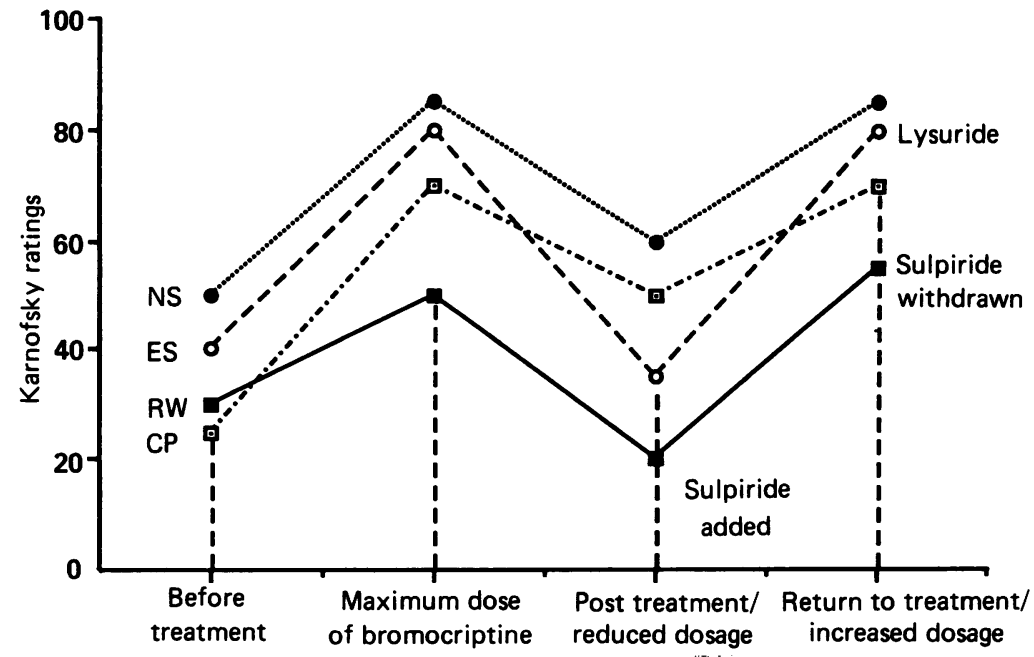

Figure Karnofsky ratings for the four cases at the four treatment stages (see text for doses).
Case 2

This 54 year old male former labourer was admitted to hospital in 1975 following a history of alcohol abuse. He was wasted, had hepatomegaly, a distal sensory neuropathy, an intention tremor and ataxic gait. Liver function tests were abnormal but thyroid and renal function tests were normal and VDRL was negative. His short term memory was severely impaired as was his drive and motivation. He was incontinent of urine and faeces, but would assist in washing himself with frequent prompting. His only spontaneous act was masturbation which he performed regardless of where he was. Even this behaviour stopped in 1987. Though ataxic he could walk, if prompted, with the help of a frame. He had a blank facial expression and answered only yes or no to questions in a flat voice, with no eye contact and often inappropriately. There had been no improvement in his state on antidepressants. He had consumed no alcohol since his admission.

Bromocriptine was started at a dose of $5 \mathrm{mg}$ daily and increased in $5 \mathrm{mg}$ stages to a maximum of $70 \mathrm{mg}$ in divided doses. On $15 \mathrm{mg}$ he began to masturbate in the ward day room, but would stop when asked. On $30 \mathrm{mg}$ he began to make occasional contributions to ward group meetings, responded more appropriately to questions, made eye contact and smiled occasionally. As the dose increased several other improvements were noted. He took himself to the toilet, and became continent. He required much less prompting to attend to his personal hygiene. Unfortunately, masturbation became an increasing problem. In an attempt to suppress this behaviour he was started on the selective dopamine antagonist sulpiride at a dose of $200 \mathrm{mg}$. Within 48 hours his masturbation had ceased but he had also reverted to his pre-bromocriptine state in all respects. Sulpiride was stopped and over a period of two weeks he gradually improved, but masturbation again started first.

\section{Case 3}

A 57 year old former miner was admitted to hospital in 1989. During the preceding three years he had become increasingly withdrawn and unspontaneous. In the month before admission he had deteriorated to the point where he was doubly incontinent, answered only yes or no to questions, and would sit or stand unmoving if not prompted. He only ate with prompting, and would sometimes continue putting spoon to mouth, sometimes for as long as two minutes after his plate was empty. Similarly he would flush the toilet repeatedly until asked to stop. There was no evidence of psychotic features before his recent deterioration, but he had suffered a brief paranoid psychosis in 1974. He was on neuroleptics over a period of four years in the 1970s and moved into a mental health hostel, where he lived until his admission, but was independent and had not been taking neuroleptic drugs for over 10 years, without relapse. In 1978 he had a brief episode of right hemiparesis and was found to 
be hypertensive. A similar episode occurred in 1984. At his recent admission he had a normal gait, but had increased tendon jerks on the right. Limb power and coordination were intact, as was sensation. A CT brain scan showed multiple low attenuation areas in the corona radiata, anterior limbs of both internal capsules and the right caudate nucleus.

He was started on bromocriptine $5 \mathrm{mg}$ per day, and increased in $5 \mathrm{mg}$ stages to a maximum of $55 \mathrm{mg}$ in divided doses. His first spontaneous activity, dressing without prompting, occurred at $20 \mathrm{mg}$. At $30 \mathrm{mg}$ he started to initiate conversations with other residents, but there was considerable day to day variation. As the dose increased, he washed, dressed and ate his meals without prompting and was not perseverative. On some days though, he reverted to his pre-treatment state. On the maximum dosage such days were rare and he was generally independent in his activities of daily living, though he continued to have occasional incontinence of urine, even on otherwise good days.

\section{Case 4}

A 62 year old female was admitted to hospital with an alcoholic amnestic syndrome, ataxia, a sensory neuropathy, and wasting. She was a former publican with a 20 year history of recurrent alcohol abuse. She had abnormal liver function tests but normal renal and thyroid function. A CT brain scan showed moderate cerebellar and cortical atrophy. Neuropsychological tests revealed impairments in logical and visual memory tasks and paired associate learning. She required frequent prompting to attend to her personal hygiene and was reluctant to walk, tending to scream if prompted to do so. Spontaneous verbal interactions were minimal and related to her basic needs. She communicated on most occasions in stereotyped phrases, which were often repeated several times in a flat voice. She had an unchanging facial expression and showed little emotion. She was often incontinent of urine if not prompted. On occasional days, however, she interacted more normally with staff and spoke of her past life. On such days she required less prompting. Because of her ataxia, she became confined to a wheelchair. She has abstained from alcohol since 1984 . Despite her evident memory problems, she had learned the names of ward staff and the geography of the ward. A trial of tricyclic antidepressants had not altered her state.

Bromocriptine was started at a dose of $5 \mathrm{mg}$ daily and increased in $5 \mathrm{mg}$ stages to a maximum of $50 \mathrm{mg}$. On $5 \mathrm{mg}$ she developed sleep disturbance which required treatment with a hypnotic (temazepam). On $10 \mathrm{mg}$ of bromocriptine she took a more spontaneous interest in her personal hygiene but was disruptive in group meetings, frequently interjecting inappropriate comments. At $20 \mathrm{mg}$ the disruptive behaviour gradually ceased and her comments became more appropriate, and she interacted spontaneously on most days with other patients and ward staff. On $30 \mathrm{mg}$ she generally required minimal prompting to attend to her personal hygiene and was showing emotion, laughing appropriately and appearing generally cheerful. She was continent, taking herself to the toilet unprompted. Further improvement occurred with further increases to a maximum of $50 \mathrm{mg}$. Two months after the prescription of the maximum dose, her mood began to decline and she was at times tearful. There was a previous history of depressive disorder, before admission and so lofepramine was prescribed. On $70 \mathrm{mg}$ she developed episodes of histrionic wailing and began to be suspicious of staff. Because of this it was decided to gradually reduce the bromocriptine. Her tearfulness and low mood was replaced by a return to her pre-treatment state. Lisuride was subsequently introduced at a dose of $200 \mathrm{mcg}$, increasing in $200 \mathrm{mcg}$ stages to $1200 \mathrm{mcg}$ in divided doses. As the dose of lisuride increased, a similar improvement occurred to that experienced on bromocriptine, but her mood remained buoyant. After some three months, she again became suspicious of staff, and would accuse them of wanting to harm her, but such episodes would last only hours. Lisuride was reduced by $400 \mathrm{mcg}$ and $10 \mathrm{mg}$ of thioridazine was added with $20 \mathrm{mg}$ of fluoxetine, an antidepressant which selectively blocks the reuptake of serotonin. At the time of writing she has been on this regime for six months without a depressive relapse and with only occasional suspiciousness.

\section{Discussion}

The cases we report justify the revival of interest in the syndrome of abulia, occurring following brain damage. The potential value of dopamine agonists in its treatment is also highlighted. This appears to apply not only when abulia is at the severity of akinetic mutism, as in previously reported cases, but also at lesser severities. Withdrawal or reduction of bromocriptine in three cases resulted in rapid deterioration, and the brief use of a dopamine antagonist (sulpiride) had a similar effect. The effectiveness of sulpiride in counteracting the beneficial effects of bromocriptine on abulia may give a clue as to the nature of the brain systems that are important in the generation of abulia. Sulpiride is a selective antagonist of D2 receptors which act independently of adenylate cyclase. ${ }^{8}$ It appears therefore that these receptors are particularly important in the mediation of drive and motivation.

In case four bromocriptine was withdrawn, due to the development of a depressive disorder. Lisuride, a recently introduced dopamine agonist of greater potency than bromocriptine, ${ }^{9}$ was introduced with good effect, but there remains the risk of a depressive relapse. The occurrence of paranoid or schizophreniform psychosis is a recognised potential side effect, but no such disorder was precipitated in case 3 , despite the fact that he had a history of paranoid illness. He had deteriorated to the point where he was very nearly akinetic, and mute, and so a trial of bromocriptine was considered justified, despite the risk of psychosis.

In addition to the abulic syndrome, which 
was common to these patients, it is interesting to note the additional features which also responded to dopamine agonists. Case 3 not only had problems initiating action, but also in ceasing actions initiated by the prompting of staff. This indicates that organic abulia may not simply be another term for apathy, or indifference, as these states could not easily explain the senseless repetitive behaviours. It seems rather that the brain systems concerned provide the mechanism by which the will or desire to act creates action, that is, a behavioural equivalent of difficulty in initiating movement which occurs in Parkinsonism. Case 4 had stereotypic repetitive speech, which appeared to be accessed in response to most attempts to communicate. An association between abulia and stereotypies in the setting of brain damage has also previously been reported. ${ }^{10}$

All of these cases had disorders producing brain damage affecting the basal ganglia and/or diencephalon. This would therefore be in line with the views of Ross and Stewart ${ }^{2}$ and others, that damage to mesolimbic dopamine systems produces abulia/akinetic mutism. The response of the alcoholically brain damaged patients (cases 2 and 4 ) is particularly interesting, as it has not previously been reported. Disorders of drive are frequently seen in association with the Korsakov's syndrome, but are overshadowed by the typical amnestic state. ${ }^{11}$ Treatment of the abulic aspect of the syndrome, when it is present, could reduce dependency, but could equally produce problems if the newly active individual has a very severe amnestic state, or severe global cognitive impairment. Case 2 was severely amnestic but did not improve to the point where the moderate increase in his spontaneity became a problem, and case 4 had impairment but not complete loss of learning ability.

Finally, whilst the results of treatment in the cases reported here are encouraging, there is clearly a need and indication for placebo controlled trials in this area, probably of a single case design.

1 Fisher CM. Abulia minor VS Agitated behaviour. Clinical Neurosurgery 1983;31:9-31.

2 Ross ED, Stewart RM. Akinetic mutism from hypothalamic damage: Successful treatment with a dopamine agonist. Neurology 1981;31:1435-9.

3 Karnofsky DA, Burchenal JH. The clinical evaluation of chemotherapeutic agents in cancer. In: MacLeod CM, ed. The evaluation of chemotherapeutic agents. New York: Columbia University Press, 1949.

4 Lidvall O, Bjorklund A, Moore RY, Stenevi U. Mesencephalic dopamine neurones projecting to the neocortex. Brain Res 1974;81:325-31.

5 Echiverri HC, Tattum WO, Merens TA, Coker SB. Akinetic mutism: pharmacologic probe of the dopaminergic mesencephalo frontal activating system Pediatric Neurology 1988;4:228-30.

6 Crismon MC, Childs A, Wilcox RE, Barrow N. The effect of bromocriptine on speech dysfunction in patients with diffuse brain injury (Akinetic mutism). Clin Neurodiffuse brain injury (Akine

7 Albert MR, Bachman DL, Morgan A, Helm-Estabrooks N. Pharmacotherapy for aphasia. Neurology 1988;38:877-9.

8 Fleet WS, Watson RT, Valenstein E, Heilman KM Dopamine agonist therapy for neglect. Neurology 1986;36 (Suppl 1):347.

9 Wachtel H, Darow R. Dual action on central dopamine function of transdihydrolisuride, a 9, 10-dihydrogenerated analogue of the ergot agonist lisuride. Life Science 1983;32:421-32.

10 Steriade M, Botez MI, Petrovici I. On certain dissociations of consciousness levels within the syndrome of akinetic mutism. Psychiatr Neurol Bael 1961;141:38-58.

11 Signoret JL. Memory and amnesias. In: Mesulam MM, ed. Principles of behavioural neurology. Philadelphia: FA Davis, 1985. 